\title{
Comparative Analysis of Root System Morphology in Tomato Rootstocks
}

\author{
David H. Suchoff ${ }^{1,4}$, Christopher C. Gunter ${ }^{1}$, and Frank J. Louws ${ }^{2,3}$
}

AdDITIONAL INDEX wORDs. Lycopersicum esculentum, WinRHIZO, grafted, specific root length, average root diameter, total root length

SuMMARY. At its most basic, grafting is the replacement of one root system with another containing more desirable traits. Grafting of tomato (Solanum lycopersi$\mathrm{cum}$ ) onto disease-resistant rootstocks is an increasingly popular alternative for managing economically damaging soilborne diseases. Although certain rootstocks have demonstrated ancillary benefits in the form of improved tolerance to edaphic abiotic stress, the mechanisms behind the enhanced stress tolerance are not well understood. Specific traits within root system morphology (RSM), in both field crops and vegetables, can improve growth in conditions under abiotic stress. A greenhouse study was conducted to compare the RSM of 17 commercially available tomato rootstocks and one commercial field cultivar (Florida-47). Plants were grown in containers filled with a mixture of clay-based soil conditioner and pool filter sand $(2: 1 \mathrm{v} / \mathrm{v})$ and harvested at 2, 3, or 4 weeks after emergence. At harvest, roots were cleaned, scanned, and analyzed with an image analysis system. Data collected included total root length (TRL), average root diameter, specific root length (SRL), and relative diameter class. The main effect of cultivar was significant $(P \leq 0.05)$ for all response variables and the main effect of harvest date was only significant $(P \leq 0.01)$ for TRL. 'RST-106' rootstock had the longest TRL, whereas 'Beaufort' had the shortest. 'BHN-1088' had the thickest average root diameter, which was $32 \%$ thicker than the thinnest, observed in 'Beaufort'. SRL in 'Beaufort' was $60 \%$ larger than ' $\mathrm{BHN}-1088$ '. This study demonstrated that gross differences exist in RSM of tomato rootstocks and that, when grown in a solid porous medium, these differences can be determined using an image analysis system.

$\mathrm{T}$ he efficacy of herbaceous grafts relies on the replacement of a scion root system with that of a rootstock with known disease resistance. The use of disease-resistant rootstocks in grafted tomato production has proven efficacious in managing numerous economically significant soilborne diseases (Kubota et al., 2008; Kunwar et al., 2015; Lee and Oda, 2002; Louws et al., 2010). In addition, certain rootstocks can improve tolerance to abiotic stress such as cold soils, salinity, drought, and flooding (Albacete et al., 2015; Colla et al., 2006; Djidonou et al., 2013; Estañ et al., 2005; He et al., 2009; Venema et al., 2008; Yetisir et al., 2006). These additional benefits afforded by certain rootstocks can

This material is based on work that is supported by the National Institute of Food and Agriculture, U.S Department of Agriculture, under award number 201101397.

${ }^{1}$ Department of Horticultural Science, North Carolina State University, Raleigh, NC 27695

${ }^{2}$ Department of Plant Pathology, North Carolina State University, Raleigh, NC 27695

${ }^{3}$ NSF Center for Integrated Pest Management, North Carolina State University, Raleigh, NC 27695

${ }^{4}$ Corresponding author. E-mail: dhsuchof@ncsu.edu. doi: 10.21273/HORTTECH03654-17 allow a grower to custom tailor the scion-rootstock combination to their local production environment and disease pressure.

Tolerance to edaphic stress has been linked to RSM. Increased TRL has been attributed to improving nutrient uptake, especially phosphorus $(\mathrm{P})$, when availability is low (Hill et al., 2006; Lambers et al., 2006). In drought conditions, increased TRL, particularly in the deeper soil profile, can improve water acquisition (Comas et al., 2013; Ho et al., 2005; Lopes and Reynolds, 2010; Schenk and Jackson, 2005; Wasson et al., 2012). A smaller root diameter may also aid water uptake in dryer conditions by reducing hydraulic resistance
(Huang and Eissenstat, 2000; Passioura, 1988; Rieger and Litvin, 1999; Sharp et al., 1988; Steudle and Peterson, 1998). A reduction in root diameter has also been observed in response to low P concentrations (Hill et al., 2006; Zobel et al., 2007) and salinity (Lovelli et al., 2012).

SRL, defined as a proportion of TRL to root dry matter, is a metric used to describe the ratio of the morphological benefit to metabolic cost in root system development (Eissenstat, 1992). An increase in $S R L$, in relation to a reduction of root diameter, has been observed as a response to low $\mathrm{P}$ (Christy and Moorby, 1975; Hill et al., 2006; Lambers et al., 2006; Schroeder and Janos, 2005), drought (Huang and Eissenstat, 2000), and salinity (Lovelli et al., 2012).

Though both intrinsic RSM and the changes observed in response to abiotic stress and reduced resources have been well studied, limited research has been conducted to compare tomato root systems. Differences by cultivar have been observed in the RSM of processing tomato (Portas and Dordio, 1979; Zobel, 1975). For tomato rootstock root systems, one hydroponic study comparing two commercial rootstocks ('Beaufort' and 'Heman') indicated differences in root density but not of average root diameter (Oztekin et al., 2009). The physical aspects of solid substrates can greatly affect root systems grown in soil compared with those in hydroponics (Chapman et al., 2012). The spatial heterogeneity of nutrient and water content within solid substrates affects both root morphology and architecture (Desnos, 2008; Forde and Lorenzo, 2001; LopezBucio et al., 2003). Hydroponic systems are designed to optimize growth by supplying roots with homogenous root zone resources. Consequently, translation of results from hydroponic

\begin{tabular}{llll}
\hline $\begin{array}{l}\text { Units } \\
\text { To convert U.S. to SI, } \\
\text { multiply by }\end{array}$ & U.S. unit & SI unit & $\begin{array}{l}\text { To convert SI to U.S., } \\
\text { multiply by }\end{array}$ \\
\hline 29.5735 & $\mathrm{fl} \mathrm{oz}$ & $\mathrm{mL}$ & 0.0338 \\
3.7854 & gal & $\mathrm{L}$ & 0.2642 \\
2.54 & inch(es) & $\mathrm{cm}$ & 0.3937 \\
25.4 & inch $(\mathrm{es})$ & $\mathrm{mm}$ & 0.0394 \\
0.0896 & inch $(\mathrm{es}) / \mathrm{oz}$ & $\mathrm{cm} \cdot \mathrm{g}^{-1}$ & 11.1612 \\
6.4516 & inch & $\mathrm{cm}$ & 0.1550 \\
1 & ppm & $\mathrm{mg} \cdot \mathrm{L}^{-1}$ & 1 \\
$\left({ }^{\circ} \mathrm{F}-32\right) \div 1.8$ & ${ }^{\circ} \mathrm{F}$ & ${ }^{\circ} \mathrm{C}$ & $\left({ }^{\circ} \mathrm{C} \times 1.8\right)+32$
\end{tabular}


studies, especially solution-based systems, to plants grown in the field or solid substrate should be done so with caution. To date, no research has been conducted comparing commercial tomato rootstock RSM in substrategrown plants.

The goal of this study was to assess tomato rootstock RSM and development in solid substrates. This information may help characterize rootstocks for their potential increase in abiotic stress tolerance observed and aid in screening and/or breeding for stress tolerance in tomato rootstocks. The specific objectives of this study were to l) compare RSM of 17 commercially available rootstocks and one commonly used tomato cultivar grown in a porous, solid substrate, at the seedling stage and 2) determine how RSM in these cultivars changes over time.

This experiment was conducted in the Marye Anne Fox Science Teaching Laboratory Greenhouses on North Carolina State University Campus, Raleigh, NC, between 15 Oct. 2015 and 21 Nov. 2015. The second trial of the study was conducted between 23 Nov. 2015 and 3 Jan. 2016. Seventeen commercially available tomato rootstocks and one common determinate tomato cultivar (Florida 47; Seminis Vegetable Seeds, St. Louis, MO) were used (Table 1).

\section{Materials and methods}

Three seeds of each cultivar were planted $2 \mathrm{~mm}$ deep in $2.8-\mathrm{L}$ black polyethylene pots with dimensions of 6 inches top diameter $\times 7$ inches height $\times 5$ inches bottom diameter (Poly-Tainer \#1; Hummert International, Earth City, MO). On emergence, seedlings were thinned to one plant per pot. Pots were lined with woven $20 \times 20$ mesh of $0.02-\mathrm{cm}^{-}$ diameter thread [about $0.016-\mathrm{cm}^{2}$ opening size (Clear Advantage Charcoal Fiber Glass Insect Screen; New York Wire, Hanover, PA)] and filled with a 2:1 (v/v) mixture of clay-based soil conditioner (Turface MVP; Profile Products, Buffalo Grove, IL) and sand (\#20 Pool Filter Sand; Aquabrite ${ }^{\circledR}$, Pleasanton, CA). This mixture was chosen as it provides a rooting medium more similar to that of the field while still allowing for easy separation and cleaning of the medium from roots (Manavalan et al., 2010). The mesh liner was used to prevent the medium from falling through the large drainage holes in the container as well as to aid in root harvest.

Plants were destructively harvested based on chronological age at 2,3 , or 4 weeks after emergence, which corresponded to the appearance of the first set of true leaves, the full expansion of the first two true leaves and the appearance of the second set of true leaves, and the full expansion of the second set of true

Table 1. List of seed companies, their locations, and tomato cultivars used in this experiment.

\begin{tabular}{lll}
\hline Company & \multicolumn{1}{c}{ City, state } & \multicolumn{1}{c}{ Cultivar } \\
\hline Sakata & Morgan Hill, CA & FTM2492 \\
Rijjk Zwaan & Salinas, CA & Emperador \\
& & Kaiser \\
& & Shield RZ \\
DP Seeds & Yuma, AZ & RST-04-106-T \\
& St. Louis, MO & RST-04-105-T \\
De Ruiter & & Shincheong gang \\
& & Cheong gang \\
& & Beaufort \\
& & Multifort \\
BHN Seed & Immokalee, FL & \\
American Takii & & BHN 1087 \\
& Salinas, CA & BHN 1088 \\
& & Armada \\
& & B.B. \\
Seminis Vegetable Seeds & & Camel \\
\hline
\end{tabular}

leaves, respectively. This resulted in 54 unique treatments ( 18 cultivars $\times$ 3 harvest dates). The experiment followed a randomized complete block design with four blocks each containing all 54 unique treatments. Each block was arranged north to south on a greenhouse bench to take into account potential variation due to sunlight gradients. Since rootstocks differed in date to emergence, the date of emergence from the soil was noted and harvest date was calculated accordingly. Greenhouse temperatures during the day were maintained at $26.7 \pm 4{ }^{\circ} \mathrm{C}$ and $18.3 \pm$ $3{ }^{\circ} \mathrm{C}$ at night. Watering occurred every $3 \mathrm{~d}$ with fertilizing applied via irrigation [200 mg. $\mathrm{L}^{-1}$ concentration of $20 \mathrm{~N}-$ 4.4P-16.6K (Peters Professional; JR Peters, Allentown, PA)] once per week.

At the time of harvest, plants and medium were pulled from the container with the aid of the mesh liner. Plants were gently excavated by hand from the medium. Once the root system was freed, the medium was thoroughly examined for any roots that may have broken off during the processing. All roots were waterrinsed of any remaining medium and placed in a container filled with $10 \mathrm{~mL}$ of $0.5 \mathrm{~g} \cdot \mathrm{L}^{-1}$ neutral red stain (Sigma Aldrich, St. Louis, MO) and stored for $24 \mathrm{~h}$ at $6.7^{\circ} \mathrm{C}$. The staining process was imposed to improve contrast and overall resolution during the scanning process as recommended by Bouma et al. (2000).

Following the staining process, roots were thoroughly rinsed for $3 \mathrm{~min}$ in deionized (DI) water before scanning. A $30 \times 42-\mathrm{cm}$ acrylic tray was placed on top of a flatbed scanner (Expression ${ }^{\circledR}$ 10000XL; Epson America, Long Beach, CA) and filled with about $2 \mathrm{~cm}$ of DI water. Roots were placed in the tray and gently positioned with no overlapping roots to allow for more uniform scanning. Scans were done in gray scale at 800 dots per inch to increase resolution of fine roots. Each image was analyzed using an image analysis system (WinRHIZO ${ }^{\text {TM }}$ version 2012b; Regent Instruments, Quebec, QC, Canada). Image analysis data collected included TRL, average root diameter, and length per diameter class (diameter classes were in increments of $0.5 \mathrm{~mm}$ ). Length per diameter class data were normalized by dividing by 
Table 2. Results from a two-way ANOVA for a fully factorial arrangement ( 18 tomato cultivars $\times 3$ harvest dates) of treatments for the combined experimental replicates.

\begin{tabular}{lrccccc}
\hline Effect & df & Total root length & Avg diam $^{\mathbf{z}}$ & ${\text { Diam class } \mathbf{1}^{\mathbf{y}}}$ & Diam class 2 $^{\mathbf{x}}$ & Specific root length $^{\mathbf{w}}$ \\
\hline Cultivar & 17 & $*$ & $* * *$ & $* * *$ & $* * *$ & NS \\
Harvest date & 2 & $* *$ & NS & NS & NS \\
Interaction & 34 & NS & NS & NS & NS & NS \\
\hline
\end{tabular}

ANOVA $=$ analysis of variance.

${ }^{\mathrm{z}}$ Average root diameter for an entire root system.

${ }^{\mathrm{y}}$ Relative diameter class calculated as total length of roots of diameter $<0.5 \mathrm{~mm}$ as a proportion of total root length; $1 \mathrm{~mm}=0.0394$ inch.

${ }^{\mathrm{x}}$ Relative diameter class calculated as total length of roots of diameter between 0.5 and $1.0 \mathrm{~mm}$ as a proportion of total root length.

wTotal root length divided by root dry weight.

Ns, ${ }^{*},{ }^{* *}{ }^{* \star *}$ Nonsignificant at $P \leq 0.05$ or significant at $P \leq 0.05,0.01,0.001$, respectively.

TRL, resulting in a ratio of diameter class root length per TRL (relative diameter class). Following scanning, roots were dried at $70{ }^{\circ} \mathrm{C}$ for $24 \mathrm{~h}$ (Thelco 130D Laboratory Oven; Precision Scientific Co., Winchester, VA) and dry weights of the total root system were taken (AE100 Digital Analytical Scale; Mettler-Toledo, Columbus, $\mathrm{OH}$ ). Dry weight measurements were used to calculate SRL (TRL/total dry weight).

Data from both trials were combined and analyzed with PROC MIXED in SAS (version 9.4; SAS Institute, Cary, NC). The model used to analyze all data contained cultivar, harvest date, and their interaction as fixed effects with trial and block nested in trial as random effects. Residual plots were studied for any violation of the assumptions in analysis of variance such as heterogeneity and outliers. No outliers were observed; however, residual plots for TRL and relative diameter class showed strong heteroscedasticity. An arcsin and log conversion was imposed on relative diameter class and TRL data, respectively, to homogenize residual variance. For reporting, data were back-transformed. When appropriate, Tukey's honest significant difference was used as a post hoc mean separation test.

\section{Results}

Initial analysis was conducted by experiment; however, there was no significant experiment $\times$ treatment interaction. Consequently, data from both experiments were combined. No significant cultivar $\times$ harvest date interactions were found for any of the response variables (Table 2). The main effect of harvest date was significant only for TRL $(P \leq 0.01)$, which increased with harvest date (Fig. 1). TRL was also significantly affected $(P \leq 0.05)$ by rootstock. 'RST-106' had the longest TRL with 'Beaufort'

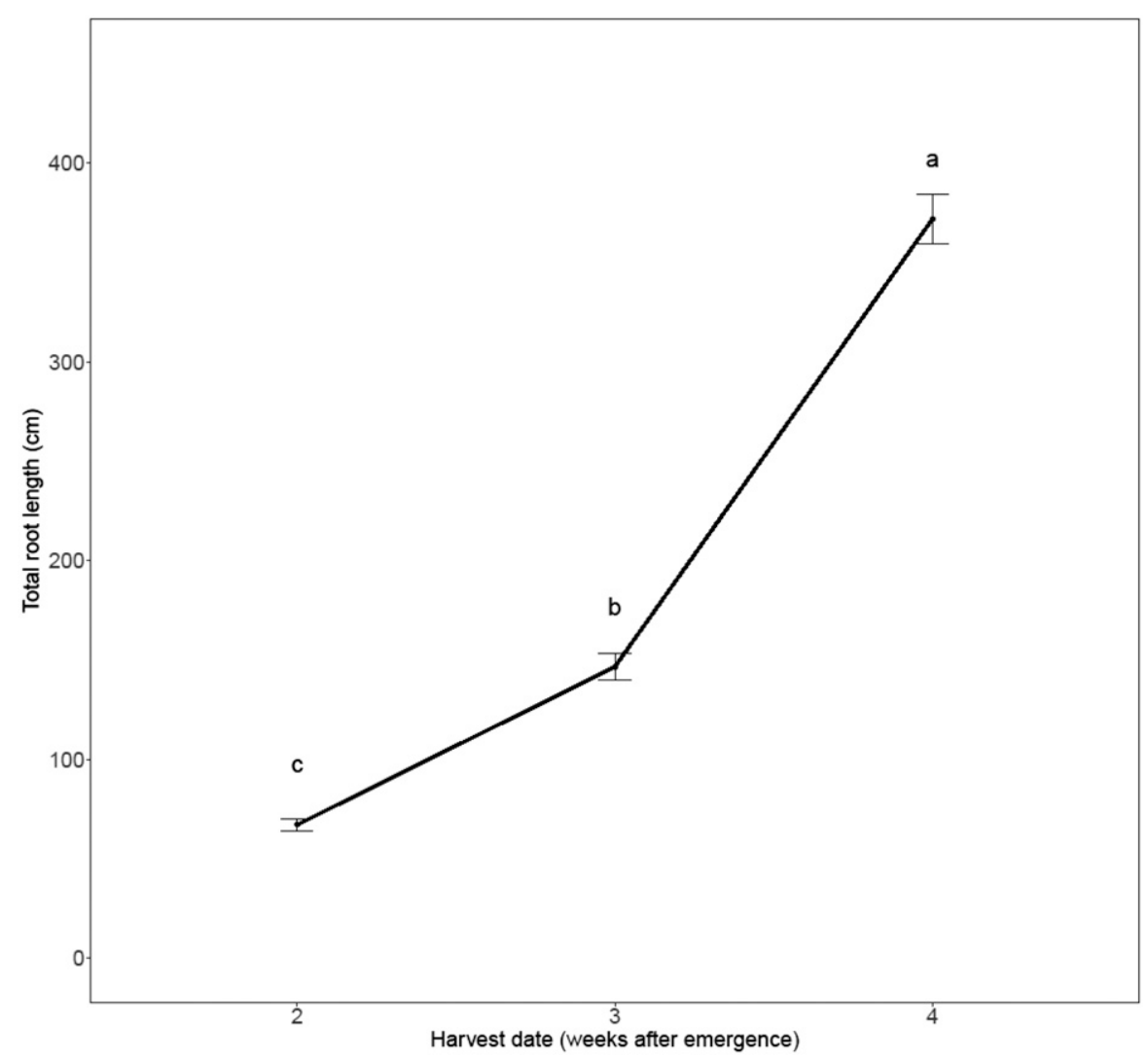

Fig. 1. Main effect of harvest in tomato rootstock total root length \pm SE over time. Means with common letters are not different (Tukey's honest significant difference at $\alpha=0.05$ ) and represent the mean of four replicate samples, 18 cultivars, and two repeated experiments $(\mathrm{n}=144$ data points for each mean $) ; 1 \mathrm{~cm}=0.3937$ inch.

having the shortest (Fig. 2). These two rootstocks represent the extremes in TRL with the remaining 16 cultivars falling in between as intermediate in their TRL. For all other response variables, the main effect of cultivar was significant at $P \leq 0.001$ (Table 2). Average root diameter was narrowest in 'Beaufort' $(0.28 \mathrm{~mm})$, 'TD-1' (0.29 mm), 'Kaiser' (0.29 mm), 'RST-105' (0.29 mm), 'Multifort' $(0.30 \mathrm{~mm})$, and 'Emperador' $(0.30 \mathrm{~mm})$ (Fig. 3). 'BHN-1088' had the widest average root diameter $(0.37 \mathrm{~mm})$ compared with all other cultivars. All remaining 11 cultivars were intermediate in the average root diameter compared with those found in the extremes.

SRL was largest in 'Beaufort' $\left(40,124 \mathrm{~cm} \cdot \mathrm{g}^{-1}\right),{ }^{\prime} \mathrm{TD}-1$ ' $\left(40,056 \mathrm{~cm} \cdot \mathrm{g}^{-1}\right)$, 'Multifort' $\left(39,333 \mathrm{~cm} \cdot \mathrm{g}^{-1}\right)$, and 'Kaiser' $\left(37,967 \mathrm{~cm} \cdot \mathrm{g}^{-1}\right)$ (Fig. 4). BHN-1088 $\left(25,147 \mathrm{~cm} \cdot \mathrm{g}^{-1}\right)$, Camel $\left(26,147 \mathrm{~cm} \cdot \mathrm{g}^{-1}\right)$, and Cheong Gang $\left(26,996 \mathrm{~cm} \cdot \mathrm{g}^{-1}\right)$ were among the cultivars that had the lowest SRL.

The majority of the TRL for all cultivars fell into diameter class 1 $[\leq 0.5 \mathrm{~mm}$ (Table 3 )]. Within this relative diameter class, 'Beaufort' had the highest proportion (0.9625) 


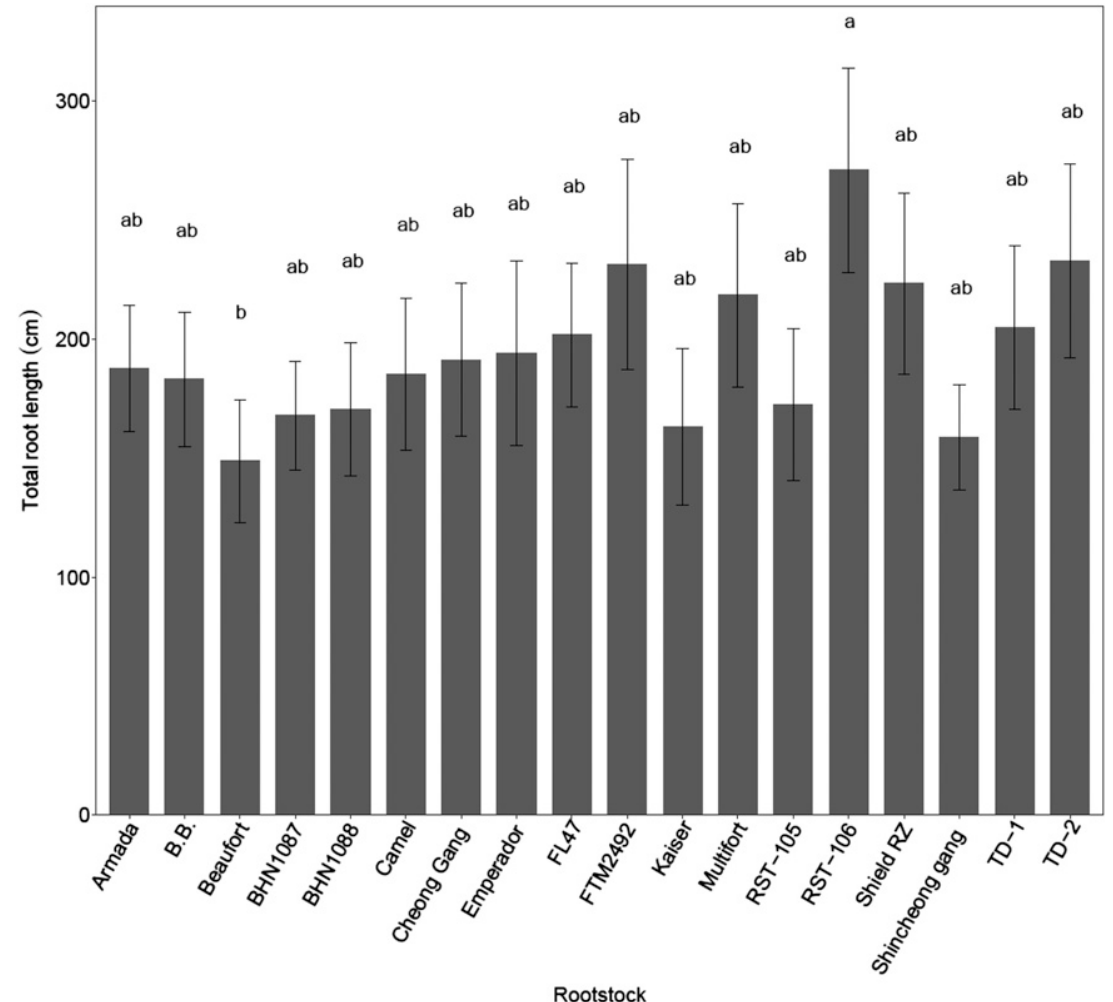

Fig. 2. Main effect of tomato rootstock on total root length \pm SE. Means with common letters are not different (Tukey's honest significant difference at $\alpha=0.05$ ) and represent the average of four replicate samples, three harvest dates, and two repeated experiments $(\mathrm{n}=24$ data points for each mean); $1 \mathrm{~cm}=0.3937$ inch.

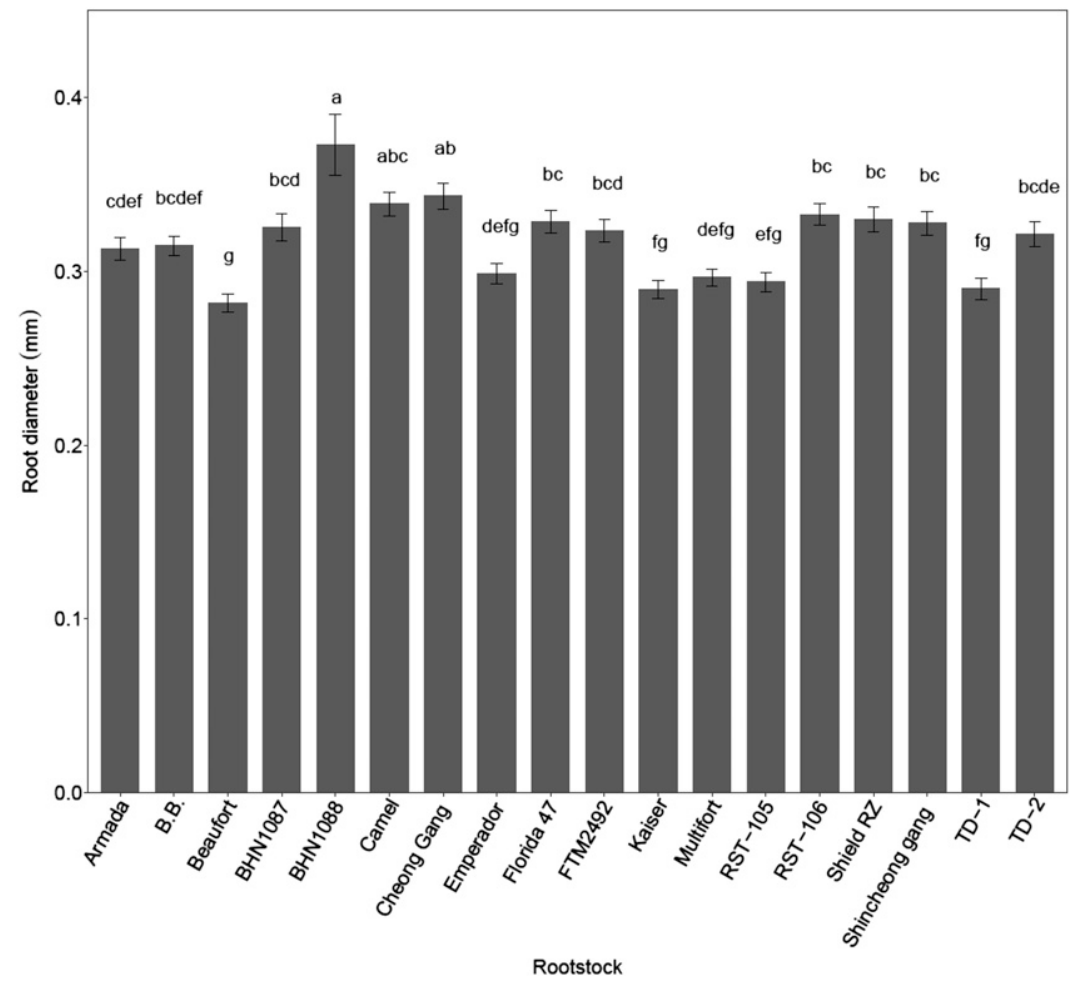

Fig. 3. Main effect of tomato rootstock on average root diameter \pm SE by cultivar. Means with common letters are not different (Tukey's honest significant difference at $\alpha=0.05$ ) and represent the average of four replicate samples, three harvest dates, and two repeated experiments $(n=24$ data points for each mean $)$; $1 \mathrm{~mm}=0.0394$ inch. followed by 'RST-105' (0.9524), 'Multifort' (0.9488), and 'Kaiser' (0.9458). 'BHN-1088' had the lowest proportion $(0.8661)$ of TRL in this relative diameter class. Results for relative diameter class $2(0.5$ to $1.0 \mathrm{~mm}$ ) were opposite to that of relative diameter class $1-$ ' $\mathrm{BHN}-1088$ ' had the highest proportion $(0.1266)$ of TRL with 'Beaufort' (0.0361), 'RST105' (0.0459), 'Multifort' (0.0498), and 'Kaiser' (0.0514) having the lowest proportion in relative diameter class 2 .

\section{Discussion}

This research indicates that quantifiable morphological differences exist between tomato rootstock root systems. Some of the differences observed may explain the improved stress tolerance provided by specific tomato rootstocks. When used as rootstocks for grafted 'Florida 47', both 'Multifort' and 'Beaufort' improved water use efficiency compared with nongrafted 'Florida 47' (Djidonou et al., 2013). The authors suggested that this improved water use efficiency may be due to root morphology. Our results with these cultivars show that SRL in Beaufort and Multifort were $41 \%$ and $38 \%$ greater than Florida 47, respectively (Fig. 4). This difference is due to both 'Beaufort' and 'Multifort' having significantly thinner average root diameters than 'Florida 47'. High SRL has been shown to increase hydraulic conductance in a trifoliate orange (Poncirus trifoliata) rootstock (Huang and Eissenstat, 2000). The authors attributed this increased hydraulic conductivity to the increased radial conductivity of the thinner rooted trifoliate orange. The increase in water use efficiency observed by Djidonou et al. (2013) may be due to the increased radial conductivity of thinner rooted 'Beaufort' and 'Multifort' rootstocks, allowing for increased hydraulic conductivity even with reduced irrigation.

At low levels of salinity $(22 \mathrm{~mm}$ sodium chloride), grafting of the tomato cultivar Belladona onto Beaufort improved yields compared with nongrafted controls (Savvas et al., 2011 ). Reduction of average root diameter and consequent increase in SRL has been demonstrated to be a response in tomato to increasing levels of salinity (Lovelli et al., 2012). 


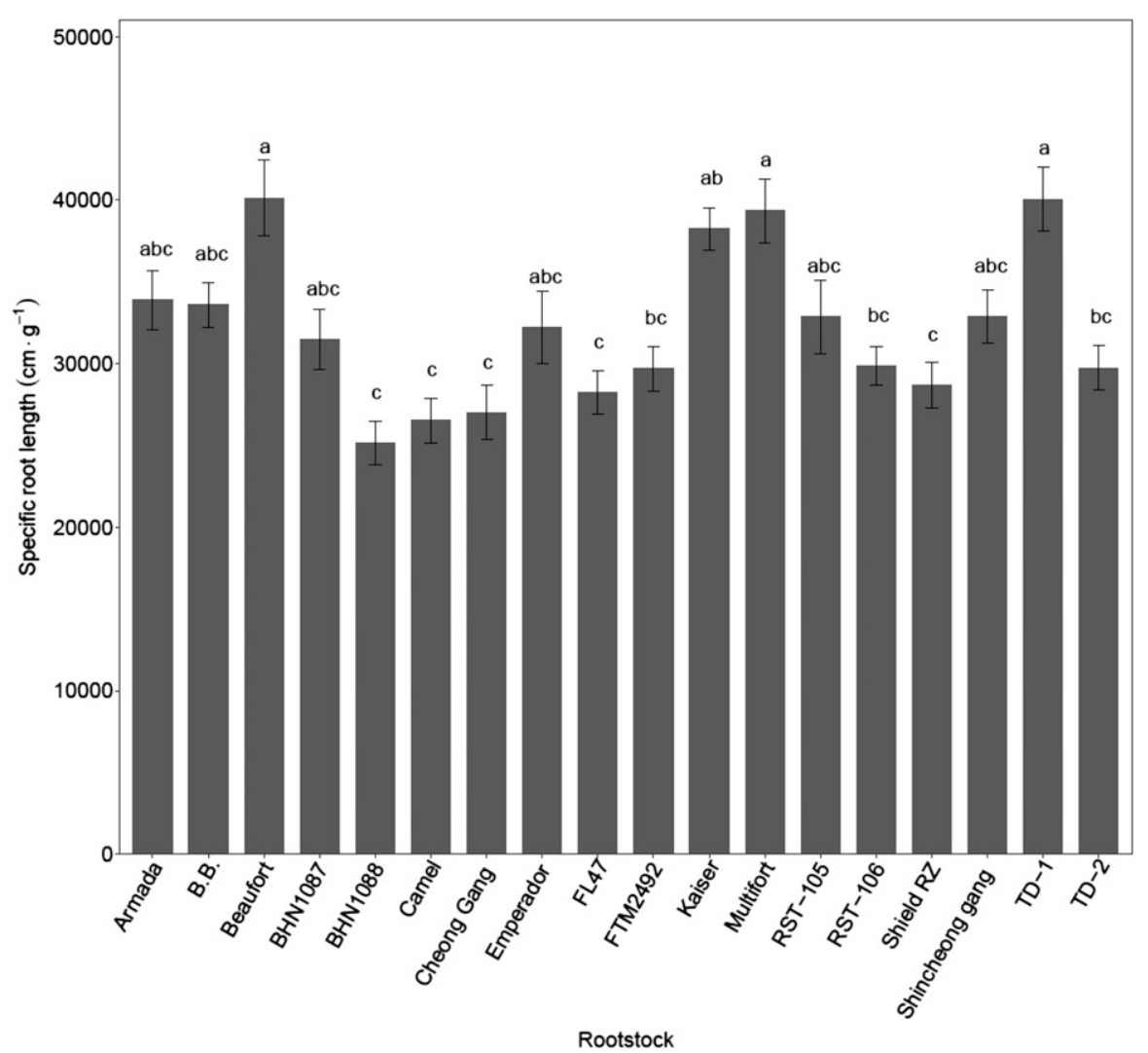

Fig. 4. Main effect of tomato rootstock on specific root length \pm SE by cultivar. Means with common letters are not different (Tukey's honest significant difference at $\alpha=0.05$ ) and represent the average of four replicate samples, three harvest dates, and two repeated experiments $(n=24$ data points for each mean $)$; $1 \mathrm{~cm} \cdot \mathrm{g}^{-1}=11.1612$ inches $/ \mathrm{oz}$.

Table 3. Main effect of tomato rootstock on proportional distribution of root diameter class.

\begin{tabular}{lcc}
\hline Cultivar & Diam class $\mathbf{1}(<\mathbf{0 . 5} \mathbf{~ m m})^{\mathbf{z}}$ & Diam class $\mathbf{2}(\mathbf{0 . 5}$ to $\mathbf{1 . 0} \mathbf{~ m m})$ \\
\hline Beaufort & $0.9625 \mathrm{a}$ & $0.0361 \mathrm{e}$ \\
RST-105 & $0.9524 \mathrm{ab}$ & $0.0459 \mathrm{de}$ \\
Multifort & $0.9488 \mathrm{abc}$ & $0.0498 \mathrm{cde}$ \\
Kaiser & $0.9458 \mathrm{abcd}$ & $0.0514 \mathrm{cde}$ \\
Emperador & $0.9417 \mathrm{abcd}$ & $0.0564 \mathrm{bcde}$ \\
TD-1 & $0.9416 \mathrm{abcd}$ & $0.0568 \mathrm{bcde}$ \\
B.B. & $0.9148 \mathrm{bcde}$ & $0.0814 \mathrm{abcd}$ \\
Shincheong Gang & $0.9142 \mathrm{bcde}$ & $0.0817 \mathrm{abcd}$ \\
Armada & $0.9124 \mathrm{bcde}$ & $0.0844 \mathrm{abcd}$ \\
BHN1087 & $0.9108 \mathrm{bcde}$ & $0.0853 \mathrm{abcd}$ \\
TD-2 & $0.9043 \mathrm{cde}$ & $0.0901 \mathrm{abcd}$ \\
FTM2492 & $0.9026 \mathrm{de}$ & $0.0924 \mathrm{abc}$ \\
RST-106 & $0.8957 \mathrm{e}$ & $0.0994 \mathrm{ab}$ \\
Florida 47 & $0.8925 \mathrm{e}$ & $0.1032 \mathrm{a}$ \\
Shield RZ & $0.8869 \mathrm{e}$ & $0.1076 \mathrm{a}$ \\
Camel & $0.8794 \mathrm{e}$ & $0.1133 \mathrm{a}$ \\
Cheong Gang & $0.8719 \mathrm{e}$ & $0.1206 \mathrm{a}$ \\
BHN1088 & $0.8661 \mathrm{e}$ & $0.1266 \mathrm{a}$ \\
\hline
\end{tabular}

${ }^{z}$ Means followed by the same letter within a diameter class are not significantly different (Tukey's honest significant difference at $\alpha=0.05$ ) and represent the average of four replicate samples, three harvest dates, and two repeated experiments $(\mathrm{n}=24$ data points for each mean $) ; 1 \mathrm{~mm}=0.0394$ inch

The authors hypothesized that the increased SRL allows for osmotic adjustment without a large investment in carbon partitioned to the roots.

Moreover, they concluded that the increase in SRL may be an adaption to increase overall root surface area, aiding in water, and nutrient uptake in saline conditions. The improved yield in tomato with 'Beaufort' rootstock at low levels of salinity also coincided with an increase in leaf calcium concentrations (Savvas et al., 2011). A separate study found that 'Beaufort' rootstock improved uptake of nitrogen, phosphorus, potassium, calcium, magnesium, and sulfur compared with self-grafted controls (Leonardi and Giuffrida, 2006). The high SRL observed in 'Beaufort' in our study may aid in improving nutrient uptake due to increased surface area.

Recent evidence suggests that shoot-derived compounds can alter root morphology (Spiegelman et al., 2015). Our study analyzed root systems from nongrafted plants. Future work is warranted to determine if scion selection alters rootstock RSM. Furthermore, studies are needed to elucidate whether the morphological traits observed in this study are static or plastic with changing edaphic environments and what the relative role RSM plays compared with physiological mechanisms in stress.

Tomato rootstocks offer growers the ability to manage soilborne diseases and ameliorate the negative effects of edaphic stress. This study demonstrates that RSM in tomato rootstocks differs by cultivar and remains similar over time, other than TRL. These differences may help explain the improved growth and production associated with specific rootstocks and could be used to classify cultivars for their suitability for use in specific growing conditions. Furthermore, the use of a porous medium coupled with scanning and analysis using an image analysis system allows for a detailed analysis of roots for plants grown in a solid substrate.

\section{Literature cited}

Albacete, A., C. Andújar, I. Dodd, F. Giuffrida, I. Hichri, S. Lutts, A. Thompson, and M. Asins. 2015. Rootstock-mediated variation in tomato vegetative growth under drought, salinity and soil impedance stresses. Acta Hort. 1086:141-146.

Bouma, T.J., K.L. Nielsen, and B.A.S. Koutstaal. 2000. Sample preparation and scanning protocol for computerised analysis of root length and diameter. Plant Soil 218:185-196.

Chapman, N., A.J. Miller, K. Lindsey, and W.R. Whalley. 2012. Roots, water, and 
nutrient acquisition: Let's get physical. Trends Plant Sci. 17:701-710.

Christy, E.K. and J. Moorby. 1975. Physiological responses of semi-arid grasses I. The influence of phosphorus supply on growth and phosphorus absorption. Austral. J. Agr. Res. 26:423-436.

Colla, G., Y. Roupahel, M. Cardarelli, and E. Rea. 2006. Effect of salinity on yield, fruit quality, leaf gas exchange, and mineral composition of grafted watermelon plants. HortScience 41:622-627.

Comas, L.H., S.R. Becker, V.C. Von Mark, P.F. Byrne, and D.A. Dierig. 2013. Root traits contributing to plant productivity under drought. Front. Plant Sci. 4:442.

Desnos, T. 2008. Root branching responses to phosphate and nitrate. Curr. Opin. Plant Biol. 11:82-87.

Djidonou, D., X. Zhao, E.H. Simonne, K.E. Koch, and J.E. Erickson. 2013. Yield, water-, and nitrogen-use efficiency in fieldgrown, grafted tomatoes. HortScience 48:485-492.

Eissenstat, D.M. 1992. Costs and benefits of constructing roots of small diameter. J. Plant Nutr. 15:763-782.

Estañ, M.T., M.M. Martinez-Rodriguez, F. Perez-Alfocea, T.J. Flowers, and M.C. Bolarin. 2005. Grafting raises the salt tolerance of tomato through limiting the transport of sodium and chloride to the shoot. J. Expt. Bot. 56:703-712.

Forde, B. and H. Lorenzo. 2001. The nutritional control of root development. Plant Soil 232:51-68.

He, Y., Z. Zhu, J. Yang, X. Ni, and B. Zhu. 2009. Grafting increases the salt tolerance of tomato by improvement of photosynthesis and enhancement of antioxidant enzymes activity. Environ. Expt. Bot. 66:270-278.

Hill, J.O., R.J. Simpson, A.D. Moore, and D.F. Chapman. 2006. Morphology and response of roots of pasture species to phosphorus and nitrogen nutrition. Plant Soil 286:7-19.

Ho, M.D., J.C. Rosas, K.M. Brown, and J.P. Lynch. 2005. Root architectural tradeoffs for water and phosphorus acquisition. Funct. Plant Biol. 32:737-748.

Huang, B. and D.M. Eissenstat. 2000. Linking hydraulic conductivity to anatomy in plants that vary in specific root length. J. Amer. Soc. Hort. Sci. 125:260-264.

Kubota, C., M.A. McClure, N. KokalisBurelle, M.G. Bausher, and E.N. Rosskopf. 2008. 1240 Vegetable grafting: History, use, and current technology status in North America. HortScience 43:1664-1669.

Kunwar, S., M.L. Paret, S.M. Olsen, L. Ritchie, J.R. Rich, J. Freeman, and T. McAvoy. 2015. Grafting using rootstocks with resistance to Ralstonia solanacearum against Meloidogyne incognita in tomato production. Plant Dis. 99:119-124.

Lambers, H., M.W. Shane, M.D. Cramer, S.J. Pearse, and E.J. Veneklaas. 2006. Root structure and functioning for efficient acquisition of phosphorus: Matching morphological and physiological traits. Ann. Bot. (Lond.) 98:693-713.

Lee, J. and M. Oda. 2002. Grafting of herbaceous vegetable and ornamental crops. Hort. Rev. 28:61-124.

Leonardi, C. and F. Giuffrida. 2006. Variation of plant growth and macronutrient uptake in grafted tomatoes and eggplants on three different rootstocks. Eur. J. Hort. Sci. 71:97-101.

Lopes, M.S. and M.P. Reynolds. 2010. Partitioning of assimilates to deeper roots is associated with cooler canopies and increased yield under drought in wheat. Funct. Plant Biol. 37:147-156.

Lopez-Bucio, J., A. Cruz-Ramirez, and L. Herrera-Estrella. 2003. The role of nutrient availability in regulating root architecture. Curr. Opin. Plant Biol. 6:280-287.

Louws, F.J., C.L. Rivard, and C. Kubota. 2010. Grafting fruiting vegetables to manage soilborne pathogens, foliar pathogens, arthropods and weeds. Sci. Hort. 127:127-146.

Lovelli, S., M. Perniola, T. Di Tommaso, R. Bochicchio, and M. Amato. 2012. Specific root length and diameter of hydroponically-grown tomato plants under salinity. J. Agron. 11:101-106.

Manavalan, L.P., S.K. Guttikonda, V.T. Nguyen, J.G. Shannon, and H.T. Nguyen. 2010. Evaluation of diverse soybean germplasm for root growth and architecture. Plant Soil 330:503-514.

Oztekin, G.B., F. Giuffrida, Y. Tuzel, and C. Leonardi. 2009. Is the vigour of grafted tomato plants related to root characteristics? J. Food Agr. Environ. 7:364-368.

Passioura, J.B. 1988. Water transport in and to roots. Annu. Rev. Plant Physiol. Plant Mol. Biol. 39:245-265.

Portas, C.A.M. and J.J.F.B. Dordio. 1979. Tomato root systems. A short review with reference on tomatoes for processing. Acta Hort. 100:113-124.

Rieger, M. and P. Litvin. 1999. Root system hydraulic conductivity in species with contrasting root anatomy. J. Expt. Bot. 50:201-209.

Savvas, D., A. Savva, G. Ntatsi, A. Ropokis, I. Karapanos, A. Krumbein, and C. Olympios. 2011. Effects of three commercial rootstocks on mineral nutrition, fruit yield, and quality of salinized tomato. J. Plant Nutr. Soil Sci. 174:154-162.

Schenk, H.J. and R.B. Jackson. 2005. Mapping the global distribution of deep roots in relation to climate and soil characteristics. Geoderma 126:129-140.

Schroeder, M.S. and D.P. Janos. 2005. Plant growth, phosphorus nutrition, and root morphological responses to arbuscular mycorrhizas, phosphorus fertilization, and intraspecific density. Mycorrhiza 15:203-216.

Sharp, R.E., W.K. Silk, and T.C. Hsiao. 1988. Growth of the maize primary root at low water potentials I. Spatial distribution of expansive growth. Plant Physiol. 87:50-57.

Spiegelman, Z., H. Byung-Kook, Z. Zhaoliang, T. Toal, S. Brady, Y. Zheng, Z. Fei, W. J. Lucas, and S. Wolf. 2015. A tomato phloem-mobile protein regulates the shootto-root ratio by mediating the auxin response in distant organs. Plant J. 83:853-863.

Steudle, E. and C.A. Peterson. 1998. How does water get through roots. J. Expt. Bot. 49:775-788.

Venema, J.H., B.E. Dijk, J.M. Bax, P.R. van Hasselt, and J.T.M. Elzenga. 2008. Grafting tomato (Solanum lycopersicum) onto the rootstock of a high-altitude accession of Solanum habrochaites improves suboptimal-temperature tolerance. Environ. Expt. Bot. 63:359-367.

Wasson, A.P., R.A. Richards, R. Chatrath, S.C. Misra, S.V. Prasad, and G.J. Rebetzke. 2012. Traits and selection strategies to improve root systems and water uptake in water-limited wheat crops. J. Expt. Bot. 63:3485-3498.

Yetisir, H., M.E. Çaliskan, S. Soylu, and M. Sakar. 2006. Some physiological and growth responses of watermelon [Citrullus lanatus (thunb.) Matsum. \& Nakai] grafted onto Lagenaria siceraria to flooding. Environ. Expt. Bot. 58:1-8.

Zobel, R.W. 1975. Genetics of root development, p. 261-275. In: J.G. Torrey and D.F. Clarkson (eds.). The development and function of roots. Academic Press, London, UK.

Zobel, R.W., V.C. Baligar, and T.B. Kinraid. 2007. Fine root diameters can change in response to changes in nutrient concentrations. Plant Soil 297:243-254. 